\title{
AURICULAR FLUTTER IN A NEWBORN BABY
}

\author{
BY \\ MURIEL M. McLEAN \\ From the Department of Child Health, University of Aberdeen and Aberdeen Maternity Hospital
}

(RECEIVED FOR PUBLICATION DECEMBER 17, 1951)

Auricular flutter is rare during childhood. Lewis's (1915) case is the first reported in the literature, and since then single cases have been reported from time to time.

In these cases the defect underlying the disturbance of rhythm is often obscure. Prince, Rotondo and Scott (1946) noted its association with congenital heart disease, O'Donovan (1929) reported it as a sequel to diphtheria, Sherman and Schless (1934) suggested that immaturity of the conducting muscle of the heart was responsible in their case, and although other authors have noted its occurrence during illnesses such as whooping cough, pneumonia and bronchitis, there has been no apparent predisposing cause in several cases.

Although a few of the affected children have been infants, I have found only three reports of this disturbance of rhythm in the newborn. Stadler (1948) and also Carr and McClure (1931) noted irregularity of the foetal heart before delivery, and although there were no symptoms in Sherman and Schless's (1934) case until the baby was 1 month old, a foetal heart rate of 190 per minute had been recorded towards the end of the pregnancy.

The following is a report on auricular flutter with varying heart block in a newborn baby.

\section{Case Report}

Mrs. A., aged 19 years, had one normal child aged 2 years and her second baby was due on May 30, 1950. She attended the hospital ante-natal clinic on March 31 and again on April 28. On the latter occasion she was found to be suffering from a microcytic hypochromic anaemia with haemoglobin of $44 \%$, and because of this she was admitted to hospital on May 5. On treatment with iron by mouth the haemoglobin had risen to $54 \%$ on May 19 , wh en treatment with intravenous iron in the form of ' ferrivenin' (Benger) was begun. On
May 30 haemoglobin was $76 \%$. During her stay in hospital the foetal heart rate was recorded on several occasions. as being difficult to count and rapid, and this began to cause concern when on the expected date of delivery it was noted that the foetal heart rate was not only rapid but very irregular. Surgical induction was performed on May 31 on the grounds that postmaturity might influence adversely the ability of the foetus to withstand anoxia, particularly as the presence of some congenital heart defect was strongly suspected.

On June 2, 17 hours after labour began, a male infant weighing $8 \mathrm{lb}$. $14 \mathrm{oz}$. was born spontaneously. Apart from slight cyanosis, which was relieved by the removal of mucus from the upper respiratory passages, he appeared healthy. Physical examination was negative apart from the cardiovascular system. The heart was not enlarged on clinical examination and no murmurs were audible, but the heart beat was very rapid and regular for periods of several minutes, beating at over 200 beats per minute, and this was followed by slower irregular beats in runs of three or four, and then for several minutes the heart would beat rapidly and completely irregularly. The baby's general condition remained good, and despite the rapid heart rate, cardiac failure did not develop.

An electrocardiographic record on June 5 showed auricular flutter with varying $2: 1$ and $3: 1$ heart block (Fig. 1). A radiograph showed enlargement of the heart and supracardiac shadow (Fig. 2). The ventricular rate remained about 200 per minute and on June 9 digitalis therapy was begun. Two minims of tincture of digitalis were given four times daily for 10 days with no effect. A further electrocardiogram on June 19 showed no change.

On June 21 it was decided to try quinidine sulphate, and after an initial dose of $\frac{1}{2}$ grain that day and $1 \frac{1}{2}$ grains the following day, 3 grains were given daily until June 28 with no effect on the rhythm. On June 27 digitalis

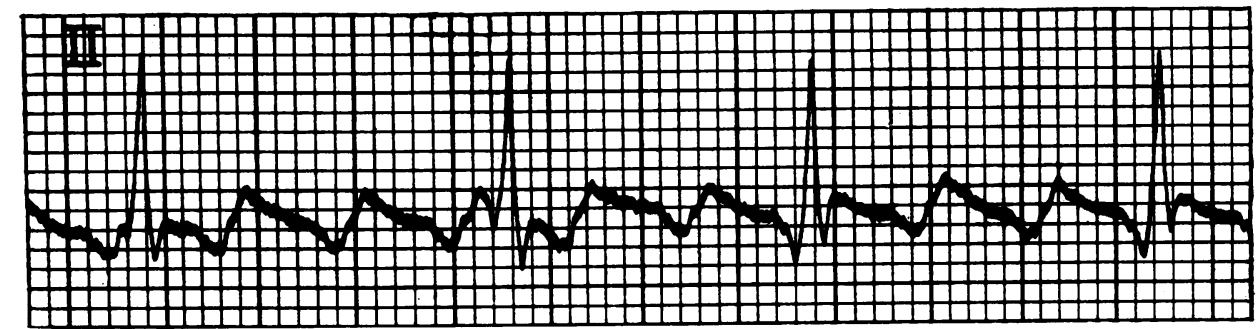

FIG. 1 


\section{AURICULAR FLUTTER IN A NEWBORN BABY}

was begun again in doses of 4 minims three times daily. During the succeeding few days, the ventricular rate fell to between 120 and 160 per minute and then on July 2 it fell to 100 per minute and became completely regular for the first time (Fig. 4). At this point digitalis was stopped and an electrocardiogram on July 3 showed normal rhythm with a ventricular rate of 120 per minute. The baby remained in hospital until July 11 , and during

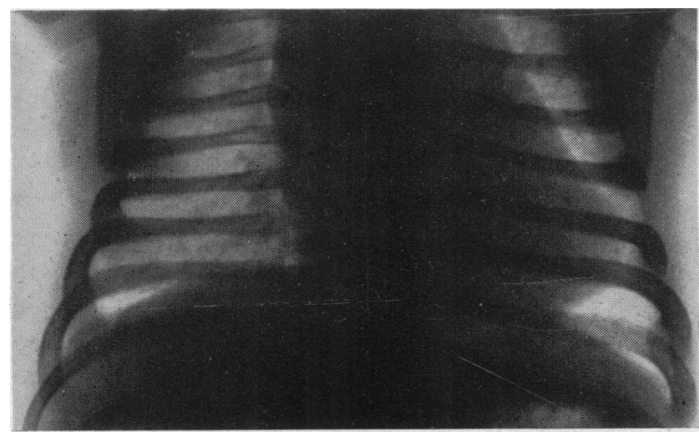

FIG. 2

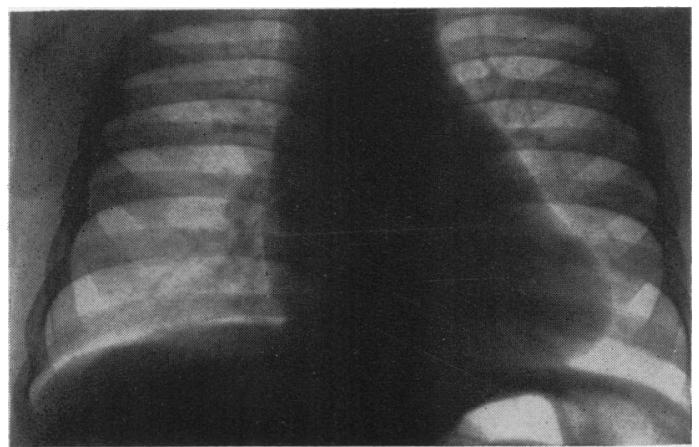

FIG. 3

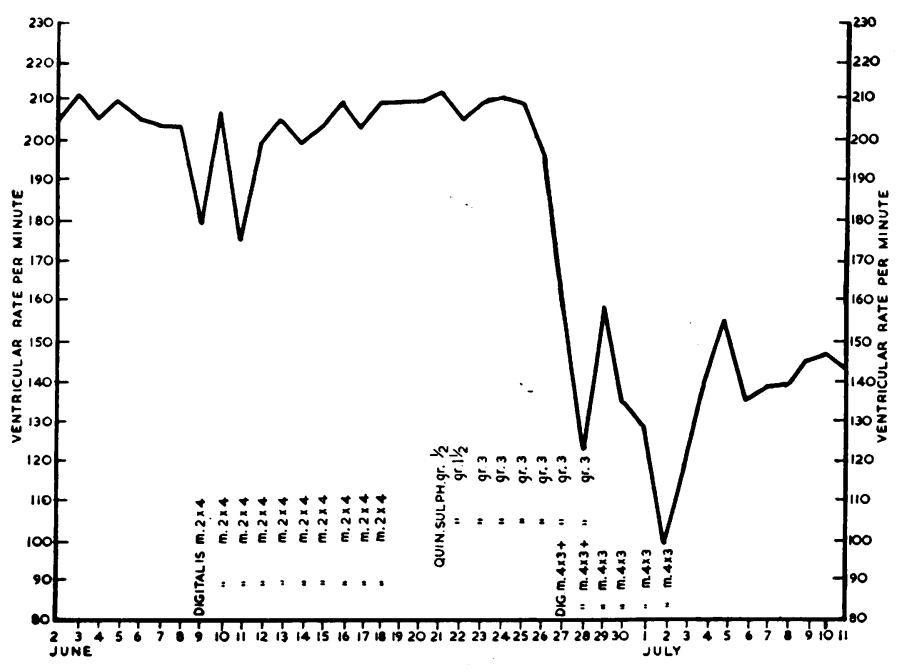

FIG. 4 this time the heart remained completely regular. On July 19 a further electrocardiogram was normal.

During the following six months the baby was seen twice, and again at the age of 1 year. He has remained very healthy and has had no illnesses. On each occasion the heart beat was regular and the electrocardiogram was normal, but a radiograph of the heart still showed an increase in transverse diameter (Fig. 3).

\section{Discussion}

This case is of interest in that the arrhythmia was noted in the foetal heart. It is also interesting to note that, despite a ventricular rate of approximately 200 per minute for a period of one month, no signs of cardiac failure were present at any time.

A review of reported cases shows that treatment in this condition is unsatisfactory. Digitalis or quinidine or both have been tried in most cases, but the results have not indicated that either drug is reliable. In Koplik's (1917) and in O'Donovan's (1929) patients normal rhythm returned spontaneously without treatment, but in these two cases the attacks were intermittent and short, the longest being two days.

In the case reported here the flutter ceased at the age of 1 month. Quinidine had no effect on the rhythm, and although the return to normal may have been spontaneous, it does seem that digitalis, when pushed to the point of auriculo-ventricular dissociation, was effective in causing the reversion to sinus rhythm.

\section{Summary}

A case of auricular flutter in a newborn infant is described. Irregularity of the foetal heart was noted two days before delivery. When digitalis was given in high dosage the cardiac rhythm became normal.

I wish to thank Professor John Craig and Dr. N. S. Clark for their criticism and advice in the presentation of this case, Professor Dugald Baird and Dr. T. Nelson for the obstetric notes, and Dr. R. J. Duthie for the electrocardiograms.

\section{REFERENCES}

Carr, J. G. and McClure, W. B. (1931), Amer, Heart J., 6,824

Koplik, H. (1917). Amer. J. med. Sci., 154, 834.

Lewis, T. (1915). Lectures on the Heart, p. 116. New York.

O'Donovan, P. (1929). Lancet, 1, 607.

Prince, G. E., Rotondo, C. C. and Scott, E. P. (1946) Amer. J. Dis. Child. 72, 552.

Sherman, J. and Schless, R. (1934). J. Pediat., 5, 802.

Stadler, H. E. (1948). Ibid., 33, 624. 